\title{
An Enterprise Architecture Methodology for Business-IT Alignment: Adopter and Developer Perspectives
}

\author{
Zulkhairi Md. Dahalin, Rafidah Abd Razak, Huda Ibrahim, \\ Nor ladah Yusop, and M.Khairudin Kasiran.
}

Utara Malaysia, Sintok, Malaysia

\begin{abstract}
This paper proposes the use of an enterprise architecture methodology known as the Systemic Enterprise Architecture Methodology to determine the relevance of EA in addressing the business-IT alignment. A construct that characterized EA was developed based on review of the literature. A theoretical framework build upon the Systemic Enterprise Architecture Methodology (SEAM) was used based on a business-IT alignment market, in which supplier business systems compete to provide a value to an adopter business system. Data was empirically gathered based on survey respondents who are concerned with the adoption, planning and implementation of EA in their organizations. Respondents were managers and executives representing the IT and senior level management of public and private organizations in Malaysia. The data collected was then analyzed based on the following factors: (1) EA business issues; (2) EA environment; (3) EA governance; and (4) EA methods, tools and frameworks. Comparative analysis was carried out based on the four factors to examine the trend and status of EA adoption and implementation in Malaysia vis-à-vis the international scenario. Statistical analysis was used to validate the SEAM, which was found to be relevant in addressing the business-IT alignment.
\end{abstract}

Keywords: SEAM, Information Management, Malaysia

\begin{tabular}{lll} 
Introduction & implementation & \multicolumn{2}{c}{ of information, } \\
Enterprise Architecture (EA) can be & $\begin{array}{l}\text { technology and business mission in } \\
\text { organizations; involving }\end{array}$ & different \\
viewed as a strategic approach in the & stakeholders and processes. & \\
evolution of the IT system in response to &
\end{tabular}
the constantly changing needs of the business environment (Schekkerman, 2006). There is no consensus on the definitions and description of EA. A common theme in all of the definitions is that EA describes principles and guidelines in governing the

Enterprise Architecture is a blueprint for how an organization achieves the current and future business objectives using IT. It examines the key business, information, application, and technology strategies and their impact on business functions

Copyright (C) 2010 Zulkhairi Md. Dahalin, Rafidah Abd Razak, Huda Ibrahim, Nor Iadah Yusop, and M.Khairudin Kasiran. This is an open access article distributed under the Creative Commons Attribution License unported 3.0, which permits unrestricted use, distribution, and reproduction in any medium, provided that original work is properly cited. Contact author: Zulkhairi Md. Dahalin email: zul@uum.edu.my 
(Pereira and Sousa, 2005). It provides the framework for planning and implementing a rich, standards-based, digital information infrastructure with well-integrated services and activities (Watson, 2000).

Organizations are always looking to find new and cost effective means to leverage existing investments in IT infrastructure and incorporate new capabilities to improve business productivity (Patrick, 2005). Hence, there is an increasing need for organizations to align their IT and business strategies. This paper examines the Systemic Enterprise Architecture Methodology (SEAM) developed by Wegmann (2003) to determine its relevance in explaining the business-IT alignment. Business-IT alignment can be defined as the adoption of appropriate IT solutions that meets the business requirements and gives satisfactory returns on the IT investment.

\section{Objectives}

This paper is set up to meet the following objectives: (1) to examine the trend and status of EA adoption and implementation in Malaysia based on international benchmark; and (2) to provide evidence of the significance of the Systemic Enterprise Architecture Methdology (SEAM) as a viable approach in validating business-IT alignment.

\section{Enterprise Architecture in Malaysia}

In Malaysia, perhaps the first known publishable article on EA appeared in a book written by Simon Seow (Seow, 2000). Ever since then and through series of workshops and seminars, as well as the setting up of the Malaysia's Chapter for the International Association of Software Architecture (IASA) in 2002, EA is becoming more and more popular among organizations based on the keen interest on the subject and the overwhelming participation among key IS players (Zulkhairi et al., 2006). However, there is still a strong need for academic involvement particularly in research and development of EA in Malaysia to further enrich the knowledge of EA.

A study conducted in 2006 on the practices of EA in selected organizations in Malaysia reveals that knowledge and understanding of EA among the organizations are poor though there had been efforts at implementing EA (Zulkhairi et al., 2006). A study by Rafidah et al. (2007) found that organizations in Malaysia, both public and private, do practice EA but the EA activities were found to be incomplete or not adequately addressed. The authors also found that knowledge on EA is very poor among the enterprise management in Malaysia. In terms of EA practice, the findings suggest variation of EA particularly at the planning stage. The study also reveals that some aspects of the EA framework were not addressed at all; whilst other aspects that were addressed vary in terms of perspectives. Earlier, Seow (2000) observed that actual EA practice among Malaysian organizations was very minimal.

\section{The Study}

Theoretical framework is a deductive reasoning approach where existing theories, ideas, constructs and methodologies are combined in search for relevant explanation to the phenomenon being studied. SEAM is based on business/IT alignment market, in which supplier business systems compete to provide a value to an adopter business system. Two units of analysis were identified in this study. First, those who are responsible for business-IT alignment (the EA Adopter); and second were those who care about EA (the EA Developer). These are people who plan, implement, advice and do consulting and collaborate with others for the development of EA in the organization. The role of the respondents in the EA Adopter is to adopt EA. The supply role in the EA Development can be broken down into 
two main actions: planning and implementation. The adoption action is mainly the responsibility of managers and staff at the operational level that drives the improvement of the business process. EA Development started with planning, which is the responsibility of senior management, and made practical through implementation, which is essentially the IT professionals. These three actions: Planning, Implementation and Adoption according to Wegmann (2003) are referred to as the EA lifecycle activities. Three groups of respondents were identified in this study to commensurate with these three actions that signify the EA activities.

Elements of the research to be studied are based on the Trends in Enterprise Architecture 2005 report by the Institute for Enterprise Architecture Development (Schekkerman, 2005). EA activities refer to the environment in which EA is present and there is evidence to suggest businessIT alignment exists through interactions of elements between business issues and the EA environmental elements. In this study, these interactions were identified based on correlation analysis that attempts to relate the EA environmental elements with the EA business issues. Relationships that are found to be significant are deemed to have supported the interactions, thereby providing evidence of business-IT alignment. The IFEAD 2005 report presented three components that make up the EA environmental elements. These are the EA Environment, the EA Governance, and the EA Methods, Tools and Framework. These three elements along with the EA business issues were incorporated into the questionnaire design as instrument used to carry out the study. A preliminary study was conducted to test the instrument and was found to be valid (Rafidah et al., 2009).

The two units of analysis mentioned in SEAM, the Adopter and the Developer, were identified as respondents in this study. EA Adopters were those users at the managerial and operational level responsible for the business-IT alignment. EA Implementers represent respondents who plan and implement the EA in the organization. This can be further subcategorized into the Planner, who are essentially the CIO, Chief Architect and IT Manager, and the Implementer, who are the Architect, Consultant and Systems Analyst.

Data collection was based on a questionnaire constructed to fulfill the needs of the two units of analysis, whereas feedbacks obtained followed the construct developed by the IFEAD 2005 report. The IFEAD report, edited by Jaap Schekkerman, President of IFEAD, consists of four dimensional constructs as represented in Table 1. The first construct, the EA Business Issues describes the respondents' perception on the business issues that EA can help addressed. Two questions were posed to operationalize the construct: 1 ) Why EA is important?; and 2) What business issues can EA help to address? Table 1 lists the complete operationalization of the four constructs adopted from the IFEAD report. 
Table 1: Dimensional construct of EA usage (adopter) and implementation (development)

\begin{tabular}{|l|l|}
\hline Dimension & Operationalized Research Elements \\
\hline EA Business Issues & $\begin{array}{l}\text { Why is EA important for your organization? } \\
\text { For what kind of issues do you plan an EA program? }\end{array}$ \\
\hline EA Governance & $\begin{array}{l}\text { Is your organization familiar with the importance of EA? } \\
\text { Is EA part of your organization's strategic governance? } \\
\text { Are you aware of any guidelines or policies related to EA in Malaysia? } \\
\text { Is there any architecture established in your organization? }\end{array}$ \\
$\begin{array}{l}\text { At which level is EA part of your organization's structure? } \\
\text { Do you have your own architect? } \\
\text { What type of architect do you have? } \\
\text { Does your organization use external architect? } \\
\text { From which external organizations do you get support in your EA } \\
\text { projects? } \\
\text { To whom is the architect reporting? } \\
\text { How are your architects educated/trained? } \\
\text { Is certification of EA by an official authority an issue? } \\
\text { How often do you plan your people to coach by experienced } \\
\text { architects? } \\
\text { How do you select a good architect coach/mentor? } \\
\text { How do you get more information about EA? }\end{array}$ \\
$\begin{array}{l}\text { What kind of EA framework does your organization used? } \\
\text { What kind of tools you use to develop EA? } \\
\text { What kind of business modeling techniques is your organization } \\
\text { using? } \\
\text { What kind of system modeling techniques is your organization using? } \\
\text { What kind of system development methodology is in use in your } \\
\text { organization? }\end{array}$ \\
\hline
\end{tabular}

EA Environment refers to the situation within the organization that makes EA present possible. EA Governance refers to the structure in which EA is being managed, including the level in which EA is positioned within the organization, the personnel involved, support structure, skills and training involved, and EA knowledge acquisition. The last construct, EA Methods, Tools and Frameworks, is concerned with the organization's adoption of a particular EA framework, the kinds of tools used to develop EA, modeling techniques used, and systems development methodology used to develop information systems that are part of the organization's EA implementation.
This study involves a sample size of 100 organizations from both public and private sectors. The sampling frame was based on the list of organizations registered in the Universiti Utara Malaysia (UUM's) University Industry Link database directory that lists more than 1260 organizations participated in the student practicum attachment throughout Malaysia. In addition, samples were also drawn from the Malaysia Computer Industry Association (PIKOM) directory, Malaysia National Computer Confederation (MNCC), MSC status companies, Federal and State Government, and IASA. Data collection involved three stages which are online, postal, and hand-delivered due to the poor response encountered in the earlier stages. A total of 500 questionnaires 
were distributed from the list based on random selection with 100 returns representing $20 \%$ response rate.

\section{Organizations Background}

Figure 1 shows the categories of organizations participated in the survey. Organizations from multinational to small organizations participated in the survey. Majority of the participating organizations (84\%) were with less than
1000 people working in the
organizations.

The participating organizations were from Kuala Lumpur (26\%), Johore (18\%), Selangor (11\%), Kedah (11\%) and smaller percentages (3-6\%) from other states. Majority are from Government organizations (46\%). Other participating organizations were IT Services, Private companies, Telecommunication companies (Telcos), Government-linked (GLCs), and Consultancy firms.

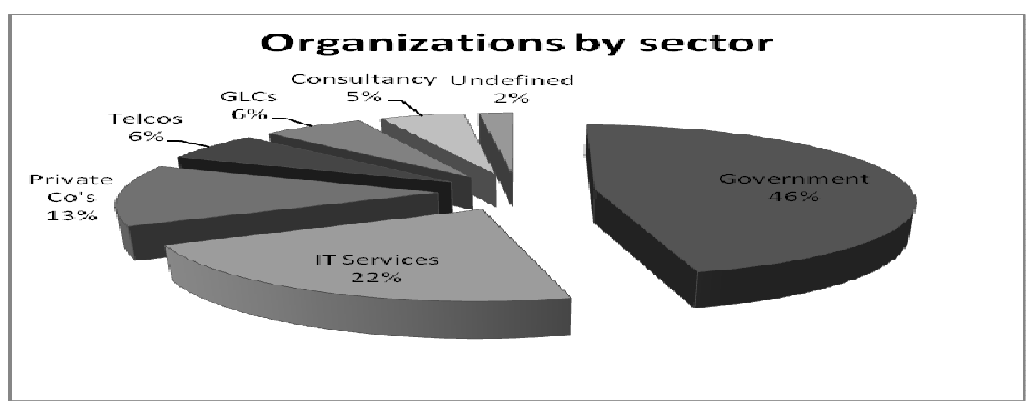

Figure 1: Categories of Organizations

The number of people working in IT department is presented in Figure 2. Sixty-one percent of the participants in the categories of $1-10$ people, $29 \%$ in the categories of $11-100$ people, $3 \%$ in the categories of 101-500 and 2\% made up the 501-1000.

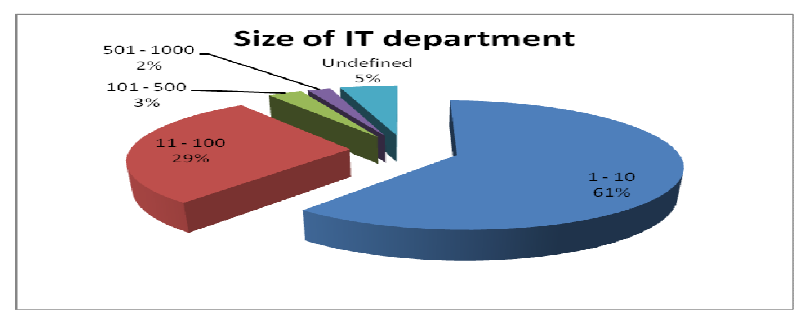

Figure 2: Number of Workers in IT Dept.

\section{The Respondents}

Table 2 listed the participating organizations category of respondents in the EA lifecycle activities. Majority of the respondents (59\%) are in the EA Implementer category, $20 \%$ of them are in EA Adopter category and $17 \%$ are in EA Planner category. Recall that EA Implementer are those IT professionals and technical people involved in implementing IT solutions that support the business-IT alignment, whilst EA Adopter is essentially the end-users who are managers and operational staff. EA Planner represents the senior level management involved in formulating the business plans and strategies. These categories of respondents were identified based on a cover letter sent to the 
organizations specifically requesting respondents who were familiar with the organization's IS and business processes to complete the questionnaire. The purpose is to ensure that those who are in the position to represent the organization in terms of EA knowledge and practices should complete the questionnaire.

Table 2: Category of Respondents

\begin{tabular}{|l|c|c|}
\hline Category & Freq & $\mathbf{\%}$ \\
\hline EA Adopter (End-users and business managers) & 20 & 20 \\
\hline EA Planner (CIO, IT managers, chief architects) & 17 & 17 \\
\hline EA Implementer (IT professionals) & 59 & 59 \\
\hline Undefined & 4 & 4 \\
\hline
\end{tabular}

\section{Enterprise Architecture Activities}

This section presents evidence of EA activities found in the study. A comparitive analysis is also carried out against an international study that was carried out and reported by the Institute for Enterprise Architecture Development (IFEAD, 2005). Consistent with the report and construction of the questionnaire instrument in this study, EA activities are categorised and presented in the following manner: (1) EA business issues; (2) EA environment; (3) EA governance; and (4) EA methods, tools and frameworks. However, there is a need to include additional factors into the EA categories in view of the dynamic nature of IT and the global business transformations that exist today. Factors such as Business-IT alignment, Customer Satisfaction, Better Work Environment, Improved Project Management, and
Service-Oriented Architecture not included in the IFEAD study were found to be important as presented in the sections that follow.

\section{EA Business Issues}

As mentioned previously, EA Business Issues describes the respondents' perception on the business issues that EA can help addressed. The question on why EA is important showed more than half of respondents (52\%) perceived business-IT alignment as the most important reason for EA to organization. These were followed by improve client's satisfaction and commitment (44\%), managing complexity, support decision making and support systems development at $43 \%$ of respondents, respectively. Figure 3 shows the rest of the reasons why EA is important and a comparison with the IFEAD 2005 report.
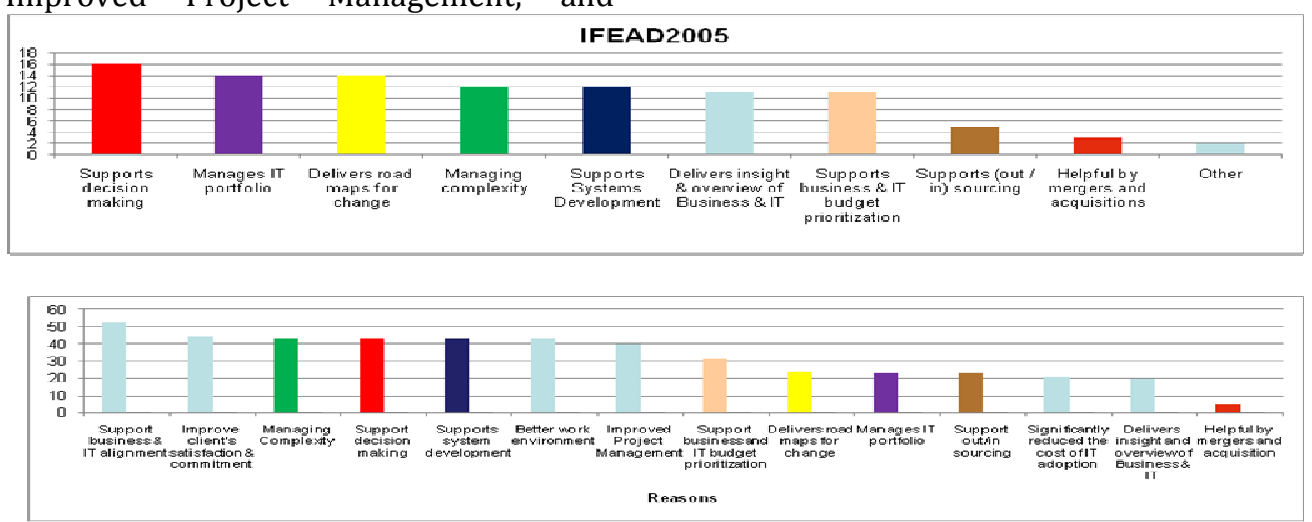

Figure 3: EA Important to Organization 
7 Communications of the IBIMA

The IFEAD 2005 findings indicate support decision making, manages IT portfolio, and delivers road maps for change as the top 3 reasons why EA is important. These were also present in the top 10 list found in this study.

On the kind of business issues that requires EA, again business-IT alignment appeared top with more than half of the respondents (55\%) perceived it as most important. This is followed by business change (35\%), application renewal (34\%), infrastructure renewal (29\%), and transformation road map (23\%). The rest are found in Figure 4 along with the IFEAD 2005 findings.

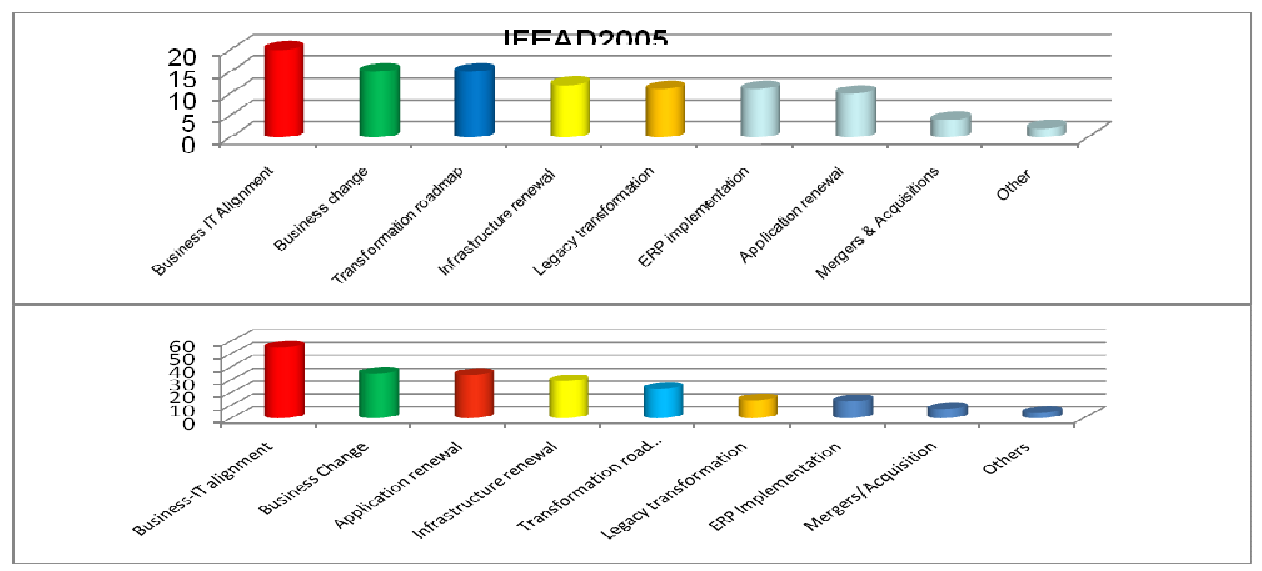

Figure 4: Business Issues that require EA

Comparison with the IFEAD 2005 shows most of the business issues that requires EA are similar across the two studies. Business-IT alignment appears to be a universal issue that requires EA. Similarly business change, application and infrastructure renewal, and transformation roadmap all deals with the dynamic nature of business where respondents believe EA should be able to address.

\section{EA Environment}

EA Environment as described previously refers to the situation within the organization that makes EA present possible. It deals with familarity of the organization with EA, policies and guidelines on EA implementation, and the presence of EA. Finding suggests slightly more than half $(52 \%)$ of respondents acknowledged that their organizations are familiar with the importance of EA. In contrast, the IFEAD 2005 report shows that almost all (95\%) of the responding organizations are familiar with the importance of EA. Figure 5 presents the comparison of the two studies.

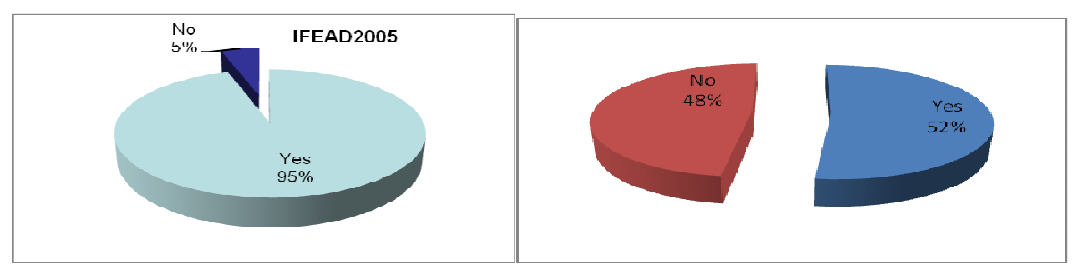

Figure 5: Familiar with EA 
Part of the studying the EA environment is to examine the commitment by organizations to establish some form of architecture. Hence respondents were asked whether they have any architecture adopted by their organizations. From the survey, $43 \%$ of the organizations have established Information Systems architecture, which was the most popular kind of architecture indicated by the respondents. Next is Software architecture at $36 \%$, followed by Governance Architecture (30\%), and Technology Infrastructure Architecture (28). The rest are presented as in Figure 6 along with a comparison with the findings reported by IFEAD 2005. Surprisingly, this study found EA at the bottom of the list, as opposed to the IFEAD 2005 report which ranked EA at the top along with Technology Infrastructure and Security architectures.

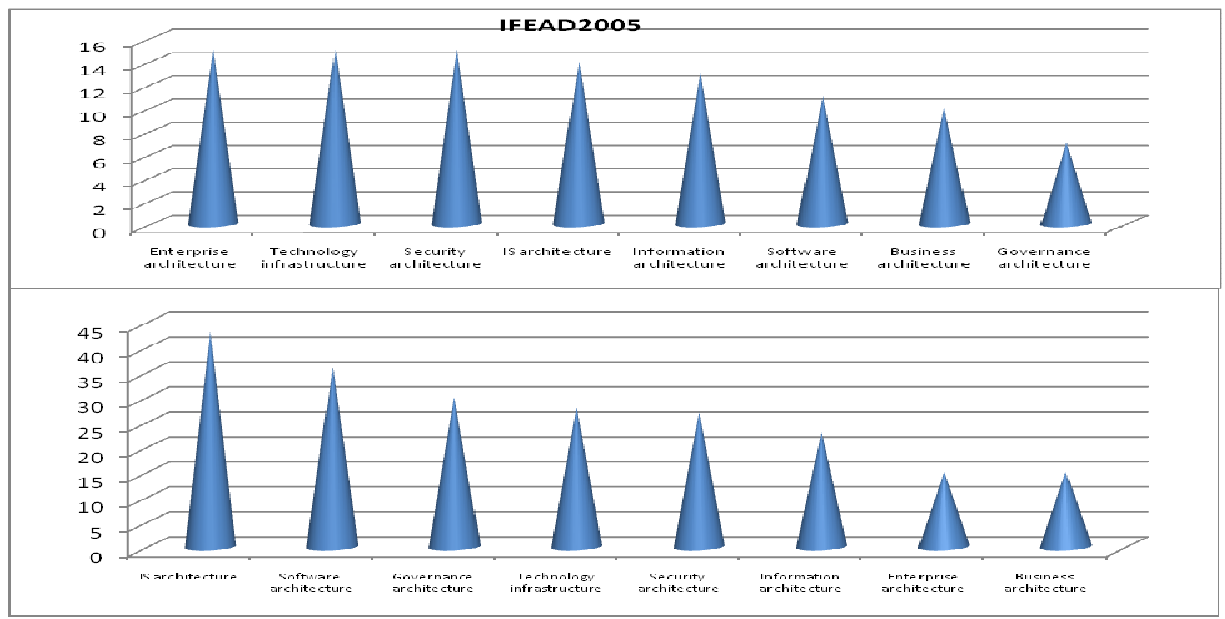

Figure 6: Kinds of Architecture established

A cross-tabulation between the public and private sectors shows a remarkable difference in terms of architecture preference. Private sector identified Software architecture as the most dorminant architecture established, however, the public sector indicated Software architecture to be among the least. Equally surprising, EA was at the bottom of the list indicated by the public sector organizations. The public sector identified IS architecture and Governance as the two kinds of architectures mostly adopted. Figure 7 presents the kinds of architectures established between the public and private sectors.

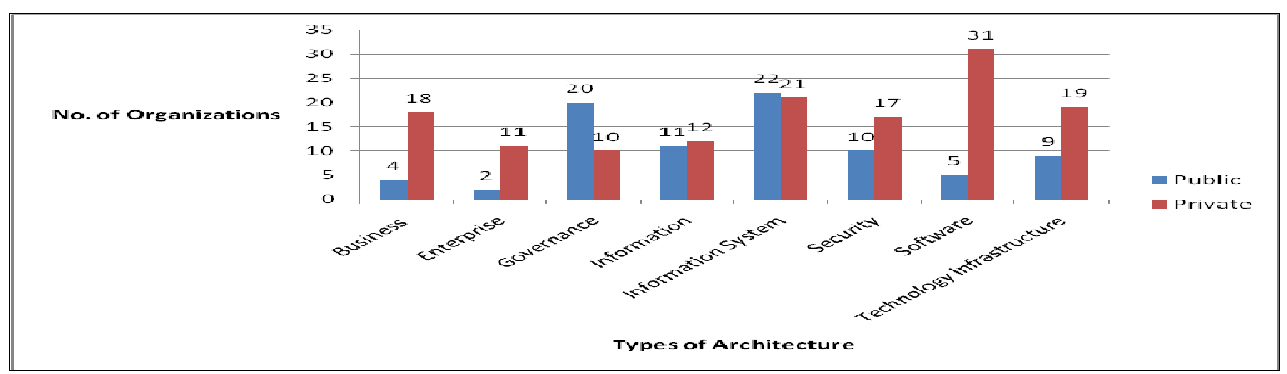

Figure 7: Cross-tabulation of architectures established in public and private sectors 
9 Communications of the IBIMA

\section{EA Governance}

EA Governance describes the management structure which reflects the conscious efforts place by the organizations in the development and adoption of EA. This study found that $50 \%$ of the organizations indicate that EA is part of their strategic governance. A cross tabulation between public and private sectors show that the private sector organizations took greater efforts in making EA part of their strategic governance. Figure 8 presents the findings based on cross-tabulation of EA Governance by public and private sectors.

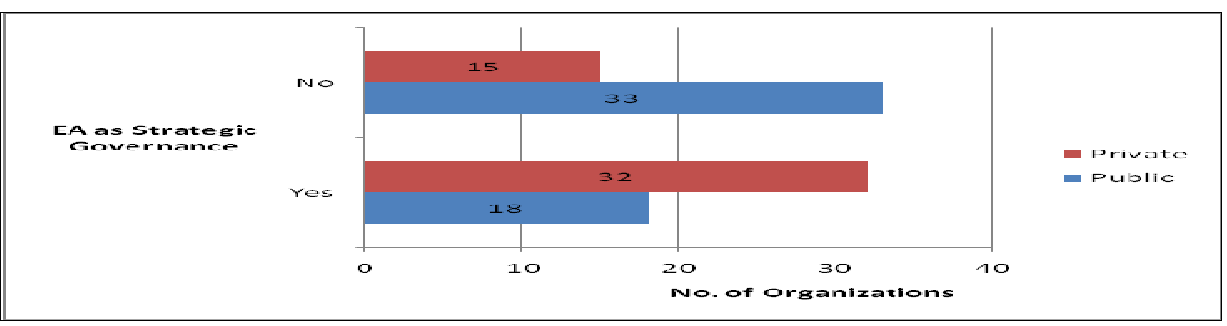

Figure 8: EA as organization's Strategic Governance

In terms of the level of EA governance structure, IT Management appears to be the preferred choice with $42 \%$ of respondents indicate EA governance structure is at their IT Management level. This is also consistent with the IFEAD 2005 report that shows similar order of EA governance structure as presented in Figure 9.

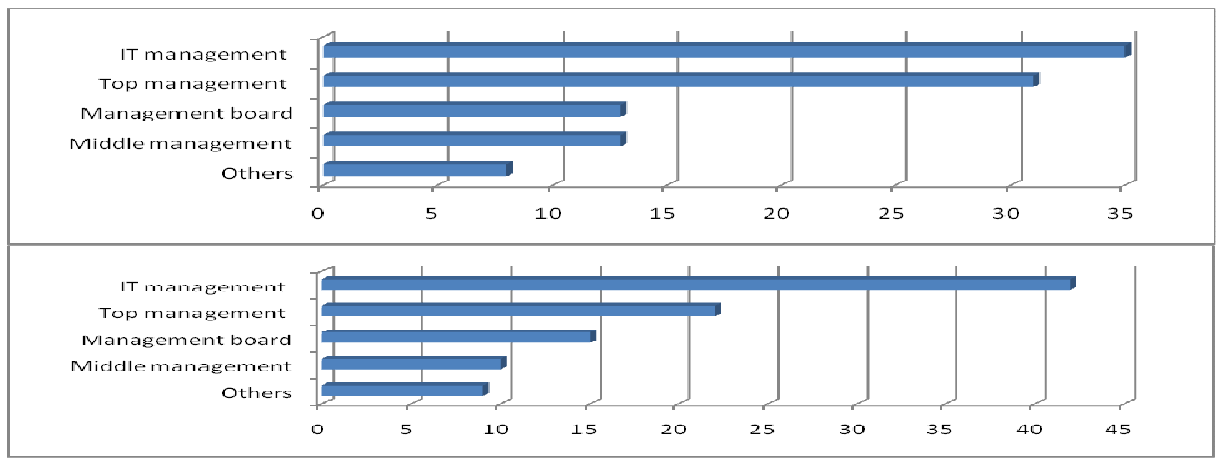

Figure 9: Level of EA Governance Structure

EA Methods, Tools and Frameworks

As has been described previously, EA Methods, Tools and Frameworks, is concerned with the organization's adoption of a particular methods, tools and framework for the development and adoption of EA. Findings from this study suggest majority of the respondents indicated using their organization's own
EA framework with $61 \%$ responses. The Service Oriented Architecture (SOA) came a far second with $18 \%$ responses. This was followedby the ISO/IEC 14252 standard architecture (IEEE 1003.0) with 9\%, and Zachman Framework with 4\% responses. 


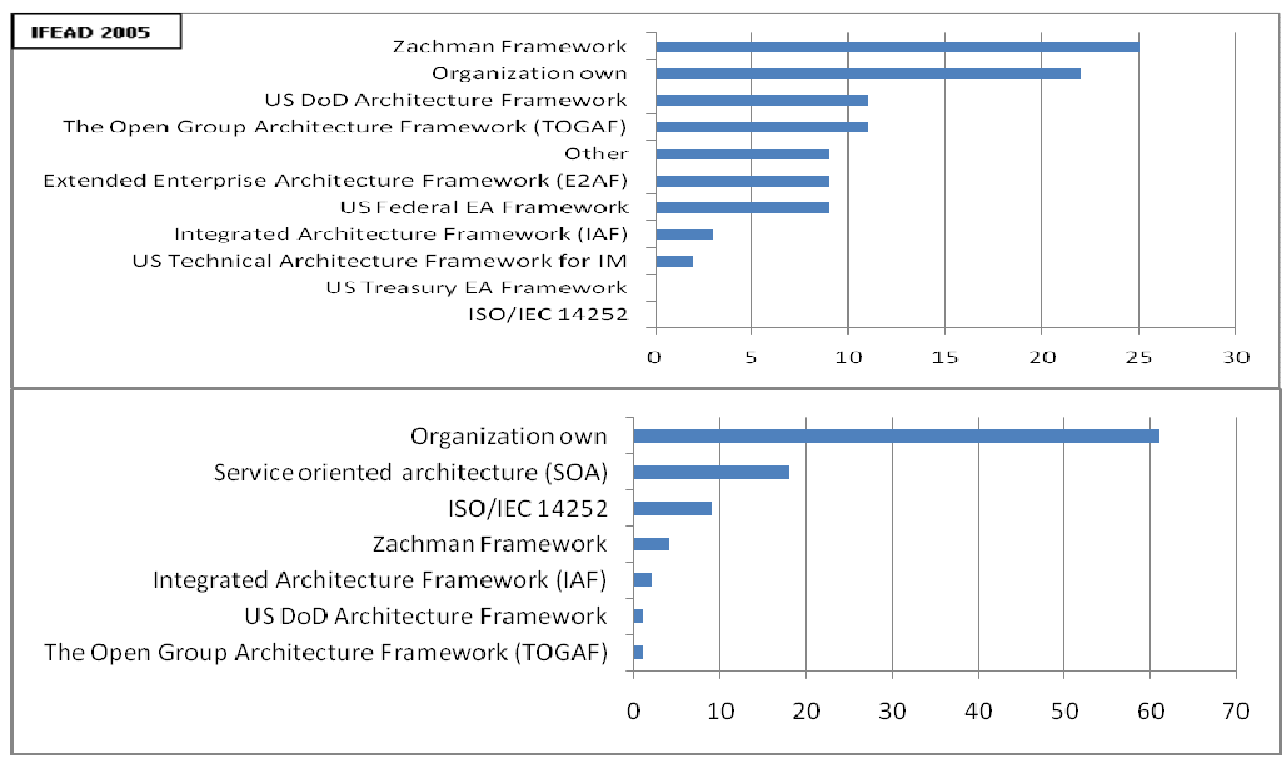

\section{Figure 10: Adoption of EA Framework}

Figure 10 presents the EA Framework adopted by the responding organizations along with the IFEAD 2005 findings. It is interesting to note that the presence of a well-known EA framework like the Zachman Framework is declining dramatically compared to the 2005 report on the trends in EA (IFEAD, 2005). What we have seen at least in Malaysia is that EA framework is still dominantly "home grown" as organizations are still grappling with the idea of an industry standard architecture that can explain how their information systems can support the organization's business objectives. One industry standard architecture that appears promising and has recently shown significant presence is the Service Oriented Architecture (SOA). In the IFEAD report 2005, SOA was not even mentioned. Today, five years down the road, SOA has become a prominent industry standard architecture and its popularity and adoption is expected to improve significantly in the future as more and more major IT players like IBM, Microsoft, SAP, Oracle etc. incorporate SOA in their service delivery.

Respondents were also asked on the methodology used for systems development. Top of the list is Rapid Application Development (RAD) with $26 \%$ of respondents indicated using the RAD approach to develop systems. The Rational Unified Process (RUP) came in second with $16 \%$ responses. A close third is the traditional system development life cycle represented by the Linear Application Development (LAD) with $15 \%$ responses. This is followed by the Dynamic System Development Method (DSDM) with $10 \%$ responses, the Iterative Application Development (IAD) with 9\% responses, Extreme Programming (8\%), and others (3\%). A significant proportion of respondents (13\%) did not used any system development methodology. 


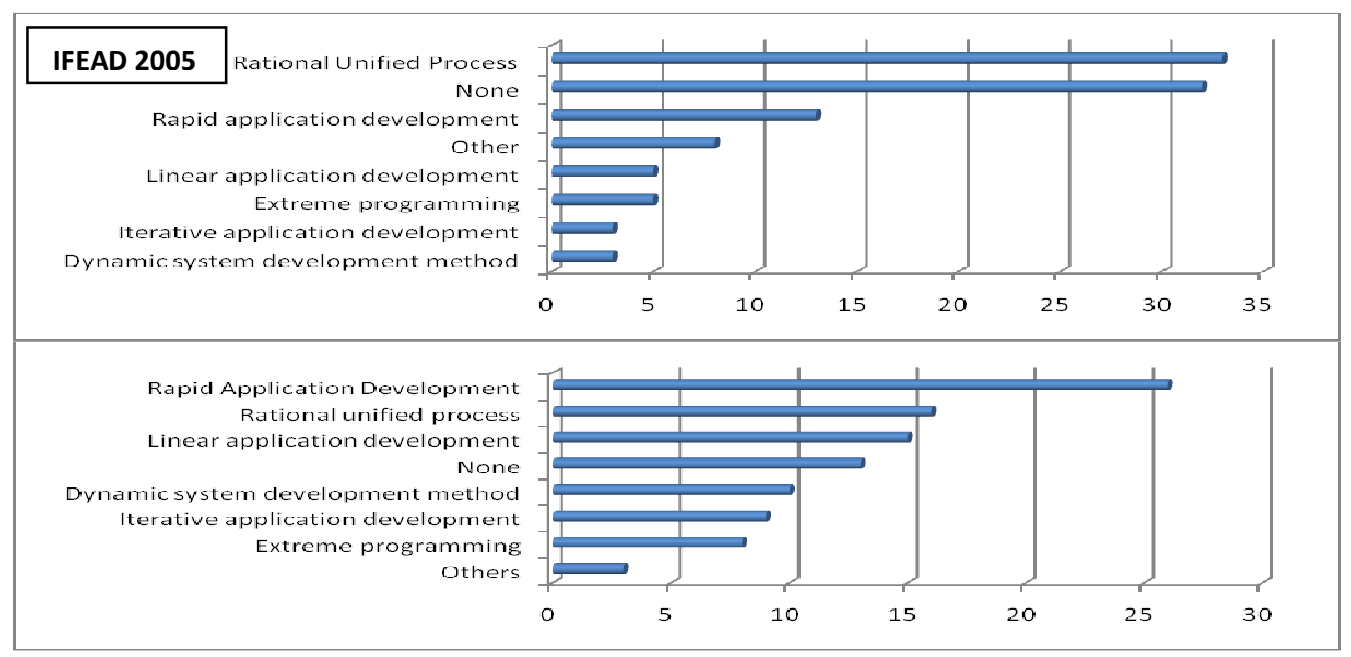

Figure 11: System Development Methodology

Figure 11 summarized the System Development Methodology in the participating organizations with comparison from the IFEAD 2005 results. Both RUP and RAD appears to be popular occupying the top 3 development methodology for EA. However, the IFEAD 2005 study is more surprising as a significant proportion of their respondents did not use any known methodology.

As for the tools to develop EA in the organizations, majority reported Microsoft Office Tools (60\%) were used to develop EA in their organizations. Almost $30 \%$ indicated using Microsoft Visio.

\section{SEAM Validation}

With evidence of EA activities presented in the foregoing section, recall that SEAM is an EA methodology proposed by Wegmann (2003) describing the business-IT alignment market in terms of the supplier business system collaborate with the adopter business system in the form of EA lifecycle activities. This section attempts to present evidence that the SEAM is a valid approach to EA development and adoption. Applying SEAM to this research, the supplier business system is represented by the EA Developer, which as mentioned in Section 4 of this paper, consists of 2 units of analysis: EA Planner and EA Implementer. The adopter business system is represented by the third unit of analysis, ie., EA Adopter. The collaboration between the EA Developer and EA Adopter in the business-IT alignment market can be illustrated by the extend relationships exist between these two elements. Using the dimensional construct of EA usage (adopter) and EA implementation (developer) as presented previously in Table 1 to signify the EA lifecycle activities, correlation analysis can be performed to determine the madnitude of relationships exist between the constructs. These relationships are presented as shown in Figure 12.

In order to test the significance of the relationships between the constructs, Intensity indices were formulated for each construct to determine the strength of the construct based on selections made by the respondents on the questionnaire instrument. Average scores of the intensity indices along with minimum and maximum scores were calculated and presented as in Table 3. 
Table 3: Intensity Indices of EA constructs

\begin{tabular}{|l|l|l|l|}
\hline Intensity Construct & Average (\%) & Minimum (\%) & Maximum (\%) \\
\hline Business Issues & 28.8 & 4.17 & 83.3 \\
\hline EA Environment & 33.0 & 0.00 & 100.0 \\
\hline EA Governance & 22.0 & 0.00 & 61.9 \\
\hline EA Methods, Tools \& Framework & 17.0 & 5.26 & 36.84 \\
\hline
\end{tabular}

Table 3 suggests that the strengths of EA activities are determined largely by the EA environment, that is familiarity of the organization to EA, the presence of EA policies and guidelines, and actual implementation of EA. EA activities are also determined by intensity of business issues, that is the need to address business changes and transformation processes. To a lesser extend, EA Governance also affect EA activities but not as much as EA Environment and Business Issues. The least average intensity score for EA Methods, Tools and Framework suggests that implementation issues, particularly the technical development of EA is less prominent than the business issues. This is despite the sample of this study constitutes nearly $60 \%$ of respondents were categorised as EA Implementers.

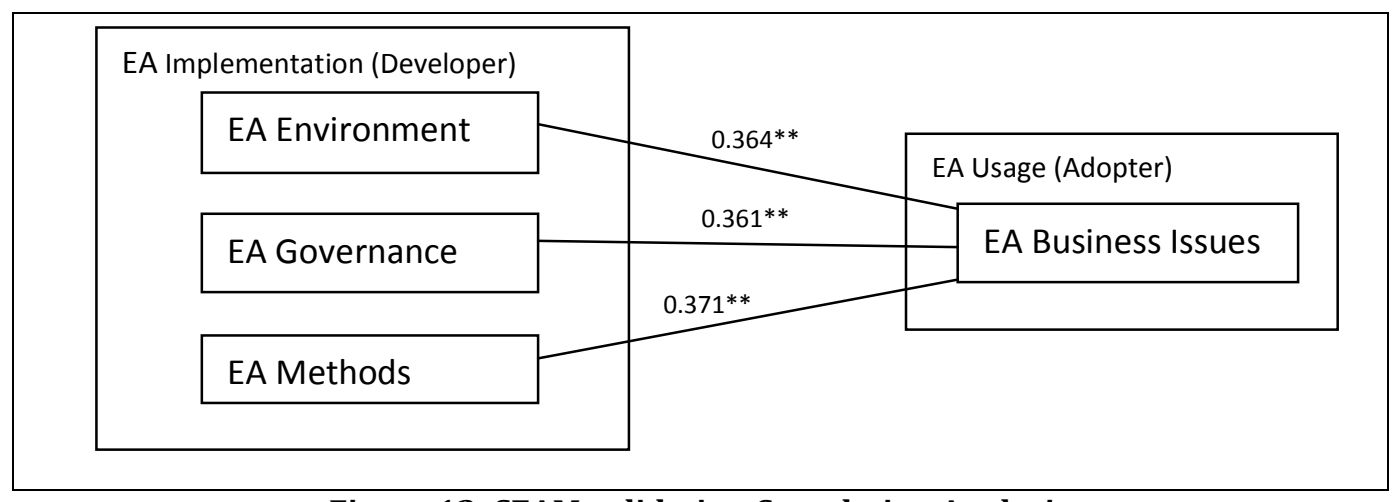

Figure 12: SEAM validation Correlation Analysis

Figure 12 shows the results of the correlation analysis between the EA Implementation (developer category constituting the EA Planner and EA Implementer) and the EA Usage (adopter category). The results suggest there exist relationships between EA Environment, EA Governance and EA Methods, Tools and Frameworks with EA Business Issues at the 0.01 significant level. Correlation coefficients reveal the magnitude and direction of relationships. The magnitude or degree of correlation between 0.36 to 0.37 as shown in the figure is considered modest. The positive relationships between the variables indicate a large (or small) values on the Developer category are associated with a large (or small) values on the Adopter category. In other words, the higher the intensity of EA Environment as signified by familiarity with EA, EA as part of organization's strategy, number and variety of architectures, and EA policy and guidelines, the higher the intensity of business issues addressed by EA. Similarly, the higher the intensity of EA Governance signified by EA formal structure, presence and levels of architects, and architects' reporting structures, the higher the intensity of business issues addressed by EA. 
Likewise, the higher the intensity of EA methods, tools and framework used by the organization, the higher the intensity of business issues that can be addressed by EA. In summary, the correlation analysis suggests that a more conducive environment for EA tends to address better business issues, whereas a stronger EA governance is likely to manage a wideranging business issues, and a more comprehensive methods, tools and framework to facilitate EA imlementation has a positive effect in addressing a wide coverage of business issues. Hence, the SEAM approach applied in this research is considered valid based on the empirical evidence presented in this section.

\section{Discussions and Conclusions}

In response to the first objective of the study, the main reasons for adopting EA found in this study are to support business and IT alignment, improve client's satisfaction and commitment, managing complexity, support systems development, support decision making, better work environment, and improve project management. Support business and IT alignment has been seen to be an important reason for EA activities in other prior studies. This suggests that organizations that want to ensure their business strategies are aligned to IT strategies should embark on EA. The significance of this alignment would ensure the organization's IT investment is justifiable. This is even strengthened by the second objective of this study, that provide evidence of the significance of the Systemic Enterprise Architecture Methdology (SEAM) as a viable approach in validating business-IT alignment.

EA is also considered important to manage road maps for change. Changes in enterprises are becoming fundamentally important because of the growing uncertainty in the global business environment today, therefore EA is important to manage these changes.
In terms of EA environment, the findings suggest that majority of the participating respondents acknowledged that their organizations are familiar with the importance of EA, though findings at the international level show a more overwhealming trend. This reveals that there is a growing interest in EA in the country, but actual EA adoption appears to be very minimal, particularly among the public sector organizations.

In terms of EA governance, the findings suggest that private sector organizations took greater efforts in making EA part of their strategic governance as compared to the public sector organizations. The findings also reveal that despite EA being considered important, it is largely the responsibility of IT managers instead of top management. This indicates a lower maturity index profile of EA governance. This is not surprising, since EA is considered a relatively new phenomenon in Malaysia. Studies done elsewhere (Schekkerman, 2005 and Matthee, 2007) show higher level of maturity with respect to EA implementations. These studies show a shift of responsibility for EA from IT managers to CEO and business managers.

On the extent of EA method, tools and framework used, dominant EA development methodologies are the Rational Unified Process and Rapid Application Development. Microsoft suites of tools almost sweep through the entire EA development activities. Majority also reported using house standards for EA framework, with growing interest in Service Oriented Architecture; whilst the more popular framework like the Zachman Framework was becoming less popular. This may suggest that organizations' preference depends much upon the industry and technology dominion, but at the same time organizations are caution in adopting new and emerging technologies. As a result, EA in Malaysia is slow to take off, but 
there is a growing interest among organizations in Malaysia towards EA as evidenced from this study.

With the SEAM approach proven viable, there is no excuse for organizations not to embark on Enterprise Architecture, as this study provides evidence that EA would be able to address an organization's business-IT alignment. Given the right environment with strategic governance in place and relevant methods, tools and framework for EA development, organizations would be able to achieve the returns on their IT investment and more importantly meeting their strategic business needs.

\section{Acknowledgement}

The authors would like to thank the Ministry of Higher Education, Malaysia and Universiti Utara Malaysia for providing the research grant for this study. Likewise, we are also indebted to Jaap Schekkerman, President of the Institute for Enterprise Architecture Developments (IFEAD) for giving us the permission to use the IFEAD EA Trend Survey Questionnaire in this study.

\section{References}

Matthee, MC., Tobin, PKJ and Merwe, PVD (2007) 'The status quo of enterprise architecture implementation in South African financial services companies,' South Africa Journal of Business Management, vol. 38, pp. 11-23.

Patrick, P. (2005) 'Impact of SOA on Enterprise Information Architectures,' presented at SIGMOD, Baltimore Maryland USA.

Pereira, CM and Sousa, P (2005) 'Enterprise Architecture: Business and IT Alignment,' presented at SAC '05, Santa Fe, NM, USA.
Rafidah, AR., Zulkhairi, MD., Huda, I., MKhairudin, K., and Nor-Iadah, Y. (2009) 'The Scenarios of Enterprise Architecture in Malaysian Organizations', presented at The 13th International Business and Information Management (IBIMA) Conference, Marrakech, Morocco.

Rafidah, AR., Zulkhairi, MD., Rohaya, D., Siti-Sakira, K., and Sahadah, A. (2007) 'Enterprise Information Architecture (EIA): Assessment of Current Practices in Malaysian Organizations,' presented at Hawaii International Conference on System Sciences (HICSS-40), Hawaii.

Schekkerman, J. (2005) 'Trends in Enterprise Architecture 2005,' Institute for Enterprise Architecture Developments (IFEAD).

Schekkerman, J. (2006) How to survive in the jungle of Enterprise Architecture Frameworks, Third Edition ed. Victoria, Canada: Trafford Publishing.

Seow, SPS. (2000) The Zachman Framework for Enterprise Architecture Finding Out More. USA: The Analyst LLC, 2000.

Watson, RW (2000) 'An Enterprise Information Architecture: A Case Study for Decentralized Organizations,' presented at The 33rd Hawaii International Conference on System Sciences, Hawaii.

Wegmann, A. (2003) 'On the Systemic Enterprise Architecture Methodology

(SEAM),' presented at the International Conference on Enterprise Information Systems, Angers, France.

Zulkhairi, MD., Rafidah, AR., Rohaya, D., Siti-Sakira, K. and Sahadah, A. (2006) 'Enterprise Information Architecture: An Assessment of Current Practices and Conditions,' Universiti Utara Malaysia, Sintok, Kedah, Research Report. 